\section{Advancing Materials and Technologies for Water Purification}

\section{Mark A. Shannon and Raphael Semiat, Guest Editors}

\begin{abstract}
Worldwide, 1.2 billion people lack access to sufficient amounts of clean water, and 2.6 billion lack adequate sanitation. Also, industry relies on large quantities of water during manufacturing, which is then returned to the environment. Having adequate water supplies, and removing pathogens, chemicals, and other contaminants with high throughput at a low cost is a growing challenge around the world. This issue of MRS Bulletin examines how materials research, through the development of membranes, catalysts, nanoparticles, and other materials, is addressing these needs.
\end{abstract}

membranes, surfaces, and particles, govern the processes.

Recent water purification advancements include the development of heterogeneous methods to disinfect, filter, and transport ions. Emerging trends and new methods include

- Disinfection: a shift from chlorine and homogeneous oxidants to heterogeneous inactivation of pathogens on metal oxide catalysts;

- Decontamination: a shift from solution concentration and disposal to catalytic mineralization of toxic compounds;

- Biological contamination control: a change from trickle gravel filters and pond biodigestion systems, which use natural microorganisms to consume organic matter, to membrane-based systems for both aerobic and anaerobic digestion;

- Filtration: from gravity sand to manufactured filters; and

- Desalination: from thermal desalination to reverse osmosis.

The key issue addressed in this issue of MRS Bulletin is that these emerging heterogeneous processes are being developed to augment or replace homogeneous chemical treatment in unit mixing processes, and they give rise to the development of new materials, testing methods, and sensing modalities.

\section{Introduction}

Access to clean water is increasingly becoming the most important issue facing people around the world. Worldwide, 1.2 billion people lack access to sufficient amounts of clean water, and 2.6 billion lack adequate sanitation. ${ }^{1}$ The combination of poor sanitation and unhealthy water quality accounts for the single largest cause of disease and death in the world. ${ }^{2}$

Clean water, according to the World Health Organization (WHO), is water that has less than the allowed concentrations of dissolved matter-a different amount depending on the constituent. Salted or polluted water contains suspended matter such as dust, algae, bacteria, viruses, and silt; organic matter such as solvents, fuel traces, pesticides, and herbicides; various salt ions above the recommended concentration; and heavy metals and more.

No other problem today is remotely close in magnitude to the need for clean water, and yet problems with water are expected to grow rapidly due to population growth imposing larger demands on the water supply for domestic use, agriculture, and energy. Moreover, water supplies are increasingly threatened due to the contamination of aquifers, the largest source of fresh water in the world, from toxic compounds to salts intruding from sea and saline sources. Salting and contamination of fresh water sources drives the need for new supplies of clean water and more extensive water treatment. As the glaciers on continents throughout the world disappear, major rivers that currently supply fresh water year-round may become intermittent, forcing the hunt for new supplies.3,4 Current water purification methods in wide use employ chemically intensive treatment that is relatively expensive, increases stress on watersheds and the environment, and is not translatable to the non-industrialized world.

Water touches every aspect of human activity, from food, health, and the environment to local and global economies. Clearly, the staggering importance of water cries out for solutions to be found and enacted.

All is not bleak, however. Many current water treatment methods are far from the thermodynamic limits. Biological disinfection, decontamination, filtering, and ion transport stand as examples of optimized systems in energetically efficient, self-cleaning, and renewable purification. A hallmark of these systems is that the interaction of species in water occurs with solid, soft materials, rather than with other liquids, as is typical in the traditional homogeneous reactor treatment systems. Interactions, both passive and active, of materials with constituents in water at an aqueous interface, such as

\section{Development Drivers}

Energy production is typically the single largest category driving the withdrawal of water from lakes, rivers, and aquifers. Vast quantities of water are used in mining, drilling, and refining of coal and oil; in cooling systems in the generation of electricity from hydro- and thermoelectric generators; and for the production of biofuels. Simply put, the increasing demand for energy is driving water use, and it will be very difficult for the world to sustain this growth without finding new ways of obtaining clean water.

Similarly, creating clean water consumes vast amounts of energy, for pumping (one of the largest uses of electric energy), desalinating, chemical production (chlorine, ammonia, ozone, etc.), and filtering. Rising energy costs are a strong driver in the development of new water purification methods.

With respect to materials development, the need to reduce energy consumption drives the development of new classes of membranes and filters. Increasing throughput for the same energy input increases efficiency, that is, increasing flux for the same pressure drop across a membrane or filter. While many materials are being synthesized with higher flux, fouling and scaling of membranes and filters 
are major inhibitors of throughput. Discovering materials and methods that reduce fouling and increase flux in total (including consideration of cleaning cycle and pretreatment) is an active area of new materials development.

Along with increasing throughput to decrease energy per unit volume, there is a growing interest in removing trace concentrations of toxic compounds from water. To decontaminate water of specific compounds, often the entire water stream is treated chemically, increasing the amount of chemicals used in the purification process. Since water can have up to parts per thousand of harmless, potable constituents, treating all the constituents to reduce toxic compounds to parts per billion and below is naturally expensive. To decrease costs and reduce the amount of energy used requires increasing the specificity and selectivity of the purification process, so that only the targeted compounds are removed or transformed to harmless compounds. Heterogeneous purification lends itself inherently to doing so via specific adsorbents and catalytic materials. Along with better removal and transformation materials, better methods to sense species with high specificity (by achieving a low number of false positives) and selectivity (high discrimination) with respect to interferents (compounds that prevent the detection of the target specie) are also needed to enable detection and mitigation of toxic compounds. Measuring trace contaminants robustly in the presence of a high background of aqueous constituents at a low cost is often one of the more difficult problems that face chemists and materials scientists. Perhaps surprisingly, water also often has extremely high variability in contamination at different locations, particularly in groundwater, and even at different times in the same location. There are thousands of potential compounds in water. If one only needs to treat water when the compounds of interest are present, water quality can be improved at lower costs.

Historically, when people speak of safe water, they are thinking of pathogen-free water. Thus, disinfecting water from microbes, viruses, and emerging agents such as prions (disease-causing proteins) that sicken people is an extremely important driver. Powerful oxidants mixed homogeneously through the solution to inactivate pathogens is the current standard treatment modality.

However, there are drawbacks to chemical treatment that are driving the development of new materials and methods for disinfection. Disinfection byproducts pro- duced by the oxidants with constituents within the water, such as nitrosoamines and polyaromatic halogens, are themselves very toxic and/or potent carcinogens. There are also protozoan parasites, such as Cryptosporidium paroum oocysts and Giardia lamblia, and viral agents that cluster within natural organic matter that are resistant to oxidation, necessitating very high concentrations of oxidants and/or long residence times in order to sufficiently disinfect the water. Filtering is then needed to separate these agents via size exclusion, which, depending on the size of the pathogen (tens of microns for protozoa, but only tens of nanometers at most for viruses) require different filter pore sizes, and thus pressure drop and energy usage. Other techniques to heterogeneously inactivate pathogens without depending on filtering by size and shape are being developed, including targeted absorption with enhanced flocculants and photocatalytic oxidation with metal oxides, such as titania compounds.

Nanoparticles, such as those shown in Figure 1, for adsorbing and mineralizing organic pollutants to harmless compounds, such as nitrogen, oxygen, carbon dioxide, and water, are being actively researched to provide a less chemically intensive alternative to advanced oxidation. Nanocatalysts are thought to work by the transfer of chemical or photon energy to form an electron-hole pair within the catalyst. When the hole comes in contact with water at the surface, according to current theories a highly reactive hydroxyl radical is thought to form, which has the capacity to oxidize hydrocarbons. Similarly, if an electron comes into contact with an oxygen molecule at the water/catalyst interface, a super oxide (such as the fast-acting $\mathrm{O}_{2}^{-}$) can form, which can subsequently reduce carbon-oxygen and nitrogen moieties that are often present in organic matter. These oxidation/reduction reactions can act to mineralize organic complexes, as well as highly toxic polyaromatic and halogenated compounds. A nice offshoot of these techniques is that they can also oxidize proteins and lipids on the surface and vesicles of pathogens that the catalysts come in contact with, thus inactivating the pathogen in water.

In all of these heterogeneous purification methods being developed, fundamental studies are needed to advance the materials science underlying these technological advancements. Even after nearly 200 years of study of aqueous solutions, a great deal of scientific study of the aqueous/material interface is still needed to be able to better design materials for a given
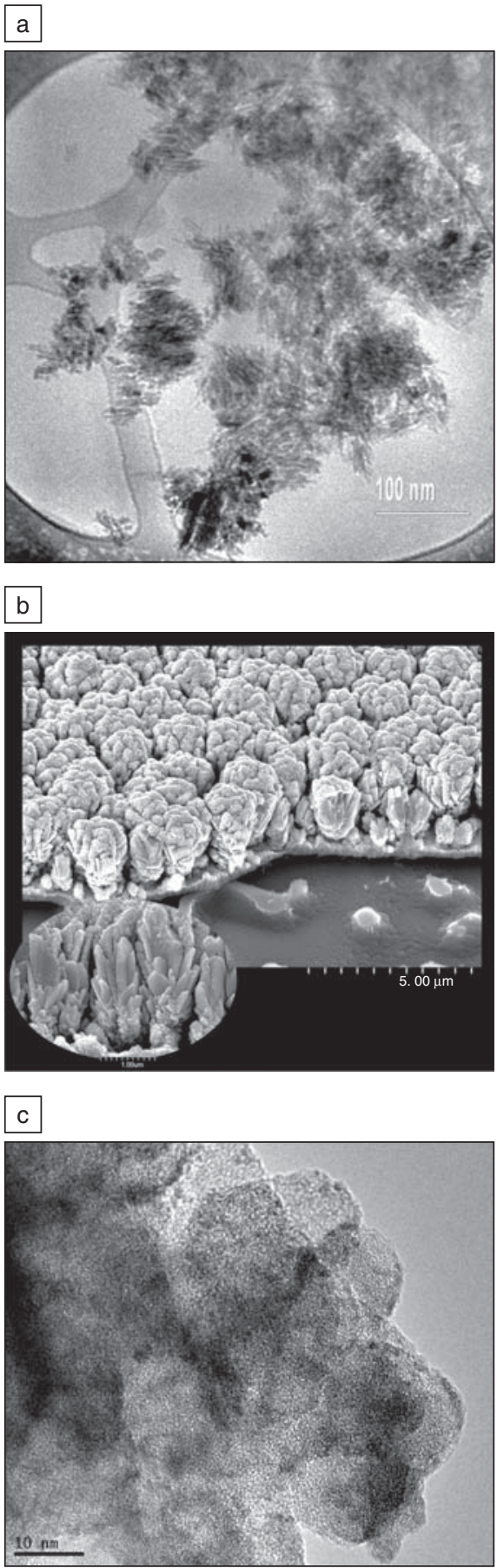

Figure 1. (a) Cryo-TEM image of a cluster of needle-like iron(III) oxidebased nanocatalysts for advanced oxidation of organic pollutants. ${ }^{5}$ (b) SEM image of a bed of tantalum pentoxide $\left(\mathrm{Ta}_{2} \mathrm{O}_{5}\right)$ photocatalysts for oxidizing organic pollutants and inactivating pathogens. (c) TEM image of nanoparticles of $\mathrm{Ta}_{2} \mathrm{O}_{5}$ on larger (micron-sized) silica particles for enhanced photo-oxidation of organic pollutants and pathogens. 
system. New methods are needed to characterize the interactions, including the physical and chemical properties and the resulting structure-property relationships of the materials, to determine, for instance, how the solute is partitioned by membranes from the solution. With knowledge gained, synthesis of membranes and filters can be guided, such as changing of pore size, surface charge, and proton donating/accepting $\left(\mathrm{pK}_{\mathrm{a}}\right)$ tendencies of the material in water. The integration of these materials into systems also needs to be analyzed, as well as the source water and any pretreatment required, such as shifting of the $\mathrm{pH}$ to be above the $\mathrm{pK}_{\mathrm{a}}$ of the material to deprotonate the surface, leaving a negative surface charge if that is desired.

Integrating the membrane and filtration systems into the modules that hold them (examples of which are shown in Figure 2) is critical. Modules strongly affect cost and performance, and determine in large part the extrinsic defects that dominate per- formance. Currently, many modules employ a spiral-wound design for membranes that promotes scaling along the contacts between the membranes and the spacers. This scaling may be avoided by new types of hollow-fiber membranes made from improved polymers, which have significantly higher transfer area per unit volume of the pressure vessel. The membranes also serve as spacers between adjacent membranes. Proper integration of materials in structures that can enhance throughput and reduce pressure vessel size and cost are necessary. This will further save equipment, volume, and plant area, thereby reducing water production costs.

\section{Articles in Issue}

In this issue of MRS Bulletin, there are five articles that cover a range of materials issues in water purification that we just discussed. The first article (Vainrot et al.) talks about the rapidly growing use of reverse-osmosis membranes in desalination to increase water supplies by desali- nating seawater at lower energy and cost than previous processes. It also describes the use of microfiltration and ultrafiltration membranes in water treatment, for instance, to reduce high biological solids content via membrane bioreactors, thus enabling reuse of water. The second article (Kaur et al.) presents the increasing use of fibrous filter media for separating out a wide range of particles in the source stream; the next generation of nanofibrous media for smaller particle size separation; and functionalized media for enhanced adsorption of specific classes of molecules in solution. The third article (Cahill et al.) presents materials characterization techniques being employed on reverse-osmosis and nanofiltration membranes to better understand how these materials interact with aqueous species to improve treatment systems. The fourth article (Wernette et al.) discusses new materials and devices being developed to sense and quantify trace contaminants in water, in particular for onsite and

a
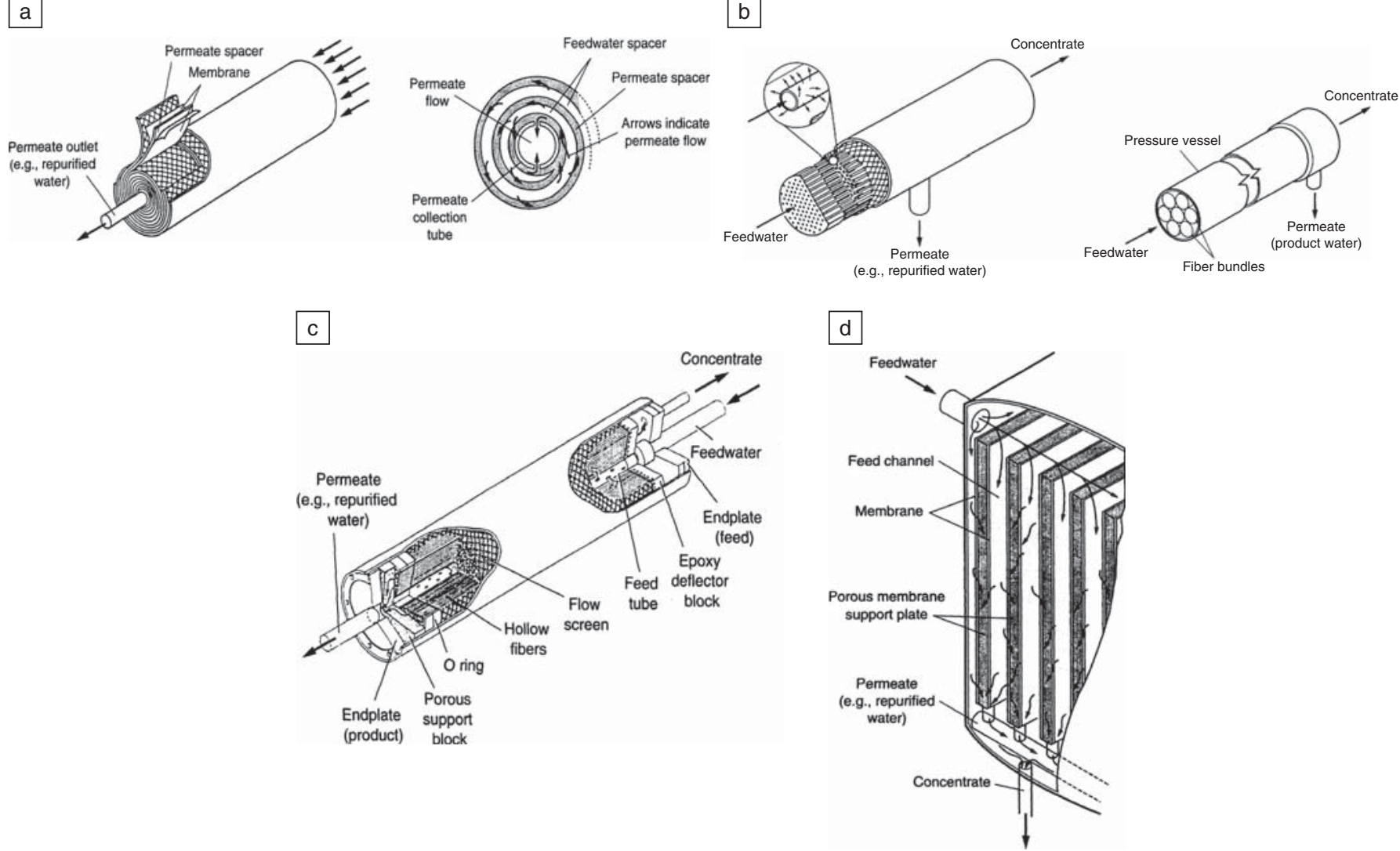

Figure 2. Schematic views of different types of membrane elements and modules, highlighting many of the materials/structure/systems issues that dominate water purification modalities in terms of cost and robustness. (a) Spiral-wound membrane and its system configuration. (b) Hollow-fiber membrane and its system configuration. (c) Elements and materials within a hollow-fiber module, highlighting the number of places where extrinsic defects and joints can cause crossover and reduced performance. (d) Similar module for flat plate membranes, which while often lower in cost than cylindrical modules, do not sustain high pressures and thus are not suitable for many current reverse-osmosis and nanofiltration systems. (From Reference 6.) 
real-time applications that can permit targeted decontamination of specific species when they are present. Finally, the fifth article (Cygan et al.) delves into the molecular basis for designing and synthesizing advanced and next-generation materials for heterogeneous purification of water for desalination, decontamination, and disinfection applications.

While these articles are not comprehensive and only touch on some of the advancements being made in materials and systems for water purification, they highlight many exciting new develop- ments, approaches, and methodologies being pursued with materials science at the core. It is our hope that readers of $M R S$ Bulletin will find many of the ideas and developments exciting as well, and that researchers throughout the world will bring their intellects, expertise, and ideas to bear in helping to solve the most pressing problem facing the world in the upcoming decades: water.

\section{References}

1. U.N. Millennium Project, Health, dignity, and development: what will it take? Task Force on Water and Sanitation (Earthscan, London, 2005).

2. World Health Organization, Water, sanitation, and hygiene links to health: facts and figures (World Health Organization, Geneva, 2003).

3. L. Shiyin, S. Wenxin, Y. Shen, G. Li, J. Glaciology 49 (8), 117 (2003).

4. T.P. Barnett, J.C. Adam, D.P. Lettenmaier, Nature 438, 303 (2005).

5. G. Zelmanov, R. Semiat, Water Res. (2007) in press.

6. G. Tchobanoglous, F.L. Burton, H.D. Stensel, Waste Water Engineering Treatment and Reuse (McGraw Hill, Boston, ed. 4, 2003).

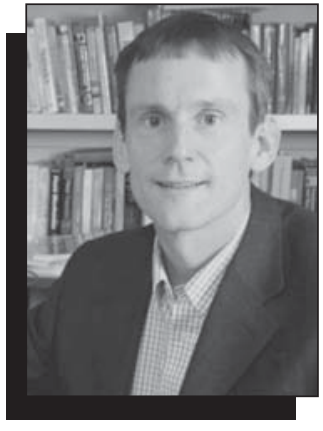

Mark A. Shannon

Mark A. Shannon, Guest Editor for this issue of MRS Bulletin, is the James W. Bayne Professor of Mechanical Science and Engineering at the University of Illinois at UrbanaChampaign (UIUC). He received his BS (1989), MS (1991), and PhD

(1993) degrees in mechanical engineering from the University of California at Berkeley.

In addition to his position on the UIUC faculty, Shannon is the director of an NSF Science and Technology Center, the WaterCAMPWS, which is a multi-university and government laboratory center for advancing the science and engineering of materials and systems for water purification for human use. He is also the director of the Micro-Nano-Mechanical Systems (MNMS)

Laboratory.

Shannon's current research includes fabrica-

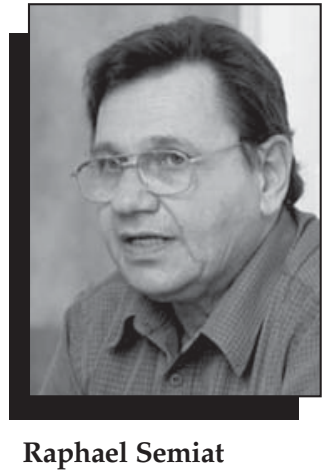

tion of micro- and nanoelectromechanical systems (MEMS and NEMS), microscale fuel cells and gas sensors, microchemical reactors and microcombustors, and micro-nanofluidic sensors for biological fluids. He is heavily involved in studying micro-nanoscale transport and systems for sensing and water purification.

Shannon can be reached at the Department of Mechanical Science and Engineering, WaterCAMPWS, University of Illinois, 1206 West Green St., Urbana, IL 61801, USA; tel. 217-244-1545 and e-mail mshannon@ uiuc.edu.

Raphael Semiat, Guest Editor for this issue of MRS Bulletin, is a professor in the Chemical Engineering Department at the Technion-Israel
Institute of Technology in Haifa, Israel. He obtained his BSc degree in chemical engineering from the Technion in 1973, defended his DSc degree dissertation on multiple effect distillation desalination in 1978, also at the Technion, and served a postdoctoral fellowship at the University of Houston.

Upon returning to Israel, Semiat joined IMI(TAMI), an R\&D subsidiary of Israel Chemicals Ltd. There, he served as the head of the Heat and Mass Transfer Engineering Research Department.

Semiat joined the Chemical Engineering Department at the Technion in 1989. He is currently director of the Grand Water Research Institute (GWRI) and in charge of the Rabin Desalination Laboratory within the GWRI. His main research interests include process development, separation processes with emphasis on desalination, solvent extraction, membrane processes, and prevention of fouling in membranes.

Semiat can be reached at the Chemical Engineering Department, Technion-Israel Institute of Technology, Technion City, Haifa 32000, Israel; tel. +972-4-8292009 and e-mail cesemiat@tx. technion.ac.il

Paul W. Bohn is the Arthur J. Schmitt Professor of Chemical and Biomolecular Engineering and a professor of chemistry and biochemistry at the University of Notre Dame. He received his BS degree in chemistry from the University of Notre Dame in 1977 and his $\mathrm{PhD}$ degree in chemistry from the University of Wisconsin-Madison in 1981. After a two-year position at Bell Laboratories, Bohn joined the faculty at the University of Illinois at Urbana-Champaign (UIUC). He remained at UIUC until August 2006, when he left to join the faculty at the University of Notre Dame.

Bohn can be reached at tel. 574-631-1849 and e-mail pbohn@nd.edu.

\section{Jeffrey Brinker is a} fellow at Sandia National Laboratories and a professor of chemical/ nuclear engineering and molecular genetics/ microbiology at the University of New Mexico. He received his $\mathrm{PhD}$ degree from Rutgers University.

Brinker is the coauthor of Sol-Gel Science (1990) with George Scherer-the most highly cited reference in the field. He has received two R\&D 100 Awards, the ACS Ralph K. Iler Award, five DOE Basic Energy Sciences Awards, the Collegiate Inventors

Award, the Ernest

Orlando Lawrence

Award, and an MRS Medal. In 2002, Brinker was elected to the National Academy of Engineering.

Brinker can be contacted at the SelfAssembled Materials Department, Sandia National Laboratories, Albuquerque, NM 871851349, USA; tel. 505-272-

7627 and e-mail cjbrink@sandia.gov.

David G. Cahill is a professor of materials science and the Willett Professor of Engineering at the University of Illinois at Urbana-Champaign (UIUC). Cahill received his $\mathrm{PhD}$ degree in condensed-matter physics from Cornell University in 1989 and worked as a postdoctoral research associate at the IBM T.J.

Watson Research Center before joining the faculty of UIUC in 1991. He is also the associate director for WaterCAMPWS, an

NSF Science and Technology Center based at UIUC.

Cahill's current research includes thermal transport at the nanoscale, thermodynamics of aqueous inter- 


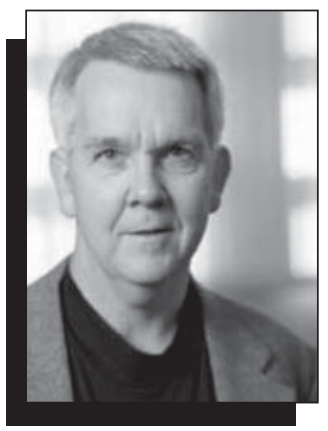

Paul W. Bohn

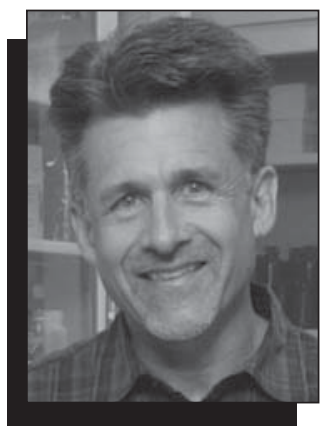

C. Jeffrey Brinker

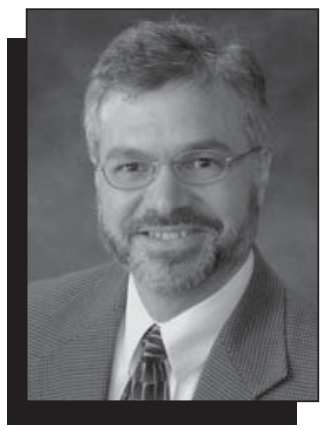

David G. Cahill

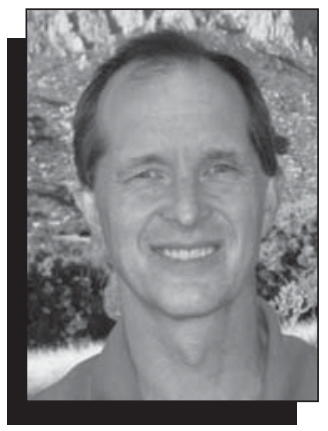

Randall T. Cygan

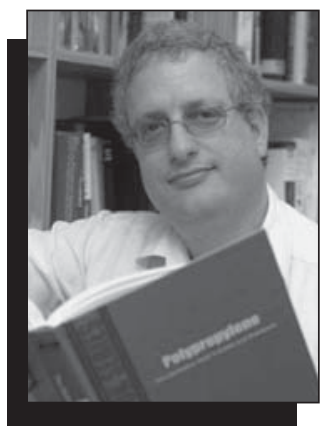

Moris S. Eisen faces, ultrafast and strongly driven transformations in materials, and the development of new experimental tools for the measurement of heat transfer and thermophysical properties.

Cahill can be reached at the Department of Materials Science and Engineering,

WaterCAMPWS,

University of Illinois, 104

S. Goodwin Ave., Urbana, IL 61801, USA; tel. 217-333-6753 and e-mail d-cahill@uiuc.edu.

Randall T. Cygan is a Distinguished Member of Technical Staff in the Geochemistry Department of Sandia National Laboratories. He earned his $\mathrm{PhD}$ degree in geochemistry and mineralogy in 1983 from the Pennsylvania State University. Cygan also spent two years as an assistant professor in the Geology Department at the University of Illinois. His research includes kinetics, chemical diffusion, mineral dissolution, adsorption phenomena, shock metamorphism, and molecular simulation. Cygan is a Centennial Fellow of the College of Earth and Mineral Science at the Pennsylvania State University and a fellow of the Mineralogical Society of America.
Cygan can be reached at the Geochemistry Department, Sandia National Laboratories, Albuquerque, NM 871850754, USA; tel. 505-8447216 and e-mail rtcygan@sandia.gov.

Moris S. Eisen is head of the Institute of Catalysis Science and Technology at the Technion-Israel Institute of Technology in Haifa, Israel. In 1990, he received his $\mathrm{PhD}$ degree in the area of catalytic activities of latetransition metal complexes from the Hebrew University in Jerusalem under the supervision of Jochanan Blum. As a Weizmann postdoctoral fellow, he joined the group of Tobin J. Marks at Northwestern University for two years of training in the area of $\mathrm{C}_{1}$-symmetry metallocene complexes for polymerizations and supported organoactinide complexes.

Eisen was a lecturer in the Department of Chemistry at the Technion from 1993 to 1996 after he received the State of Israel Alon Fellowship. He became a senior lecturer in 1997, an associate professor in 1999, and a full professor in 2003. He has been head of the Institute of Catalysis Science and Technology since 2004, and since 2006, he has held the Samuel O. Friedlander Academic Chair in Chemistry.

His research interests cover many areas of polymers and organometallic chemistry, including the design of early-transition complexes for the polymerization and copolymerization of polar and nonpolar monomers, the synthesis and reactivity of organoactinide complexes for demanding chemical transformations, and synthetic membranes for desalination and sensing. In 2000, he received the Meitner-Humboldt Award for Research. Eisen also received the Mitchel Soref Research Award in 2001 and the Henry Taub Prize in 2002.

Eisen can be reached at the Technion-Israel Institute of Technology, Technion City, Haifa 32000 , Israel.

Viatcheslav Freger is a senior lecturer at the Zuckerberg Institute of Water Research and the Department of Biotechnology and Environmental Engineering at Ben Gurion University (BGU) in Beer-Sheva, Israel. He received his $\mathrm{PhD}$ degree in chemical engineering from BGU in 1999 and worked as a postdoctoral research associate at the University of Bath before joining the faculty of BGU in 2000.
His current research focuses on the fundamentals of membrane separations, membrane formation and modification, the development of new tools for membrane characterization, and the thermodynamics of swelling and partitioning of molecules and ions in polymers.

Freger can be reached at Zuckerberg Institute for Water ResearchZIWR, The J. Blaustein Institutes for Desert Research, Ben Gurion University of the Negev, Sede-Boqer Campus, 84990, Israel; tel. +972-856-3532 and e-mail vfreger@bgu.ac.il.

Renuga Gopal is a vice president of product development for and founder of BioMers Pte. Ltd., a medical device company in Singapore. She earned a BE degree with honors in mechanical engineering and an ME degree in bioengineering from the National University of Singapore (NUS) in 2001 and 2003, respectively.

Recently, Gopal completed her PhD degree in mechanical engineering at NUS on the influence of electrospun architecture. Her research interests include nanofibrous media for separation technology and composite technology.
Gopal can be reached at 3425 Radio Rd., Suite 204, Bldg. B, Naples, FL 34104 USA.

\section{Satinderpal Kaur is a} research officer in the Department of Mechanical Engineering at the National University of Singapore (NUS). Kaur received her ME degree in mechanical engineering and her BSc degree in chemistry from NUS in 2007 and 2002 respectively. Her research focuses on modifying the surface of electrospun nanofibers for expanding their application in water treatment.

Kaur can be reached at National University of Singapore, Nanoscience and Nanotechnology Initiative, Faculty of Engineering, Blk E3-0512 Nanobioengineering Lab, 2 Engineering Dr. 3, Singapore 117576; tel. +65-5616-4272 and e-mail satinpal@gmail. com.

Seung-Yeop Kwak is an associate professor of materials science and engineering at Seoul National University in Korea. He received his $\mathrm{PhD}$ degree (1992) in polymer engineering from the University of Akron, Ohio, and worked as a senior researcher at the Korea Institute of Science and Technology (KIST) before 


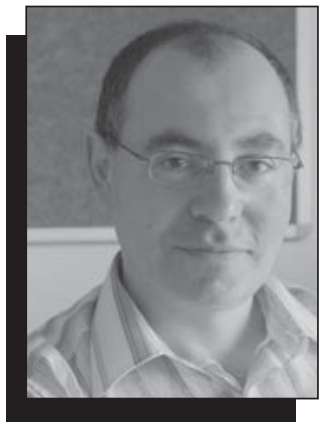

Viatcheslav Freger

joining the faculty of Seoul National

University in 1996.

His current research includes ecological hybrid materials free from endocrine disruptors; functionalized reverse-osmosis and ultrafiltration membranes; ion-conducting polymer membranes for lithium batteries and direct methanol fuel cells; and analyses of nanostructure and molecular motion by solid-state nuclear magnetic resonance, positron annihilation lifetime, and dynamic mechanical spectrometry.

Kwak can be reached at the School of Materials Science and Engineering, Seoul National University, San 56-1, Sillim-dong, Gwanak-gu, Seoul 151744, Korea; tel. +82-2880-8365 and e-mail sykwak@snu.ac.kr.

Kevin Leung is a staff member at Sandia

National Laboratories, where he has been for eight years. He received his $\mathrm{PhD}$ degree in theoretical chemistry from the University of California at Berkeley. Currently working in the Surface and Interface Sciences Department at Sandia, Leung's research interests include $a b$ initio molecular dynamics and atomistic simulations of

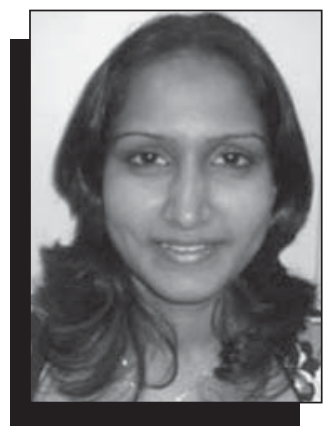

Renuga Gopal

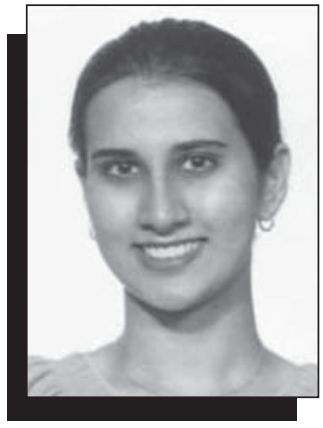

Satinderpal Kaur

Yi Lu is an HHMI

Professor and an alumni research scholar in the Departments of

Chemistry, Biochemistry, and Materials Science and Engineering at the University of Illinois at Urbana-Champaign (UIUC).

He received his $\mathrm{PhD}$ degree from the University of California at Los Angeles in 1992. After two years of postdoctoral research at the California Institute of Technology, Lu joined the Department of Chemistry at UIUC.

Lu can be reached at tel. 217-333-2619 and e-mail yi-lu@uiuc.edu.

Juewen Liu is a postdoctoral research associate at the University of New Mexico with C. Jeffrey Brinker. Liu received his $\mathrm{PhD}$ degree in the Department of Chemistry of the University of Illinois at Urbana-Champaign in 2005 , under the direction of Yi Lu.

Liu then worked for two years at DzymeTech Inc., a startup company commercializing functional DNA sensor technology.

Liu can be reached at the University of New

Mexico, Advanced

Materials Laboratory,

1001 University Blvd. SE, MS 1349, Albuquerque, NM 87106, USA; e-mail liujw@unm.edu.

Takeshi Matsuura is professor emeritus in the Department of Chemical Engineering at the University of Ottawa. He obtained his DIng degree at the Institute of Chemical Technology of the Technical

University of Berlin in 1965.

Matsuura is a fellow of the Chemical Institute of Canada and a member of the North American Membrane Society and the Chemical Society of Japan. He received the International

Desalination and

Environmental

Association's research award in 1983. In 1996, a symposium of membrane gas separation was

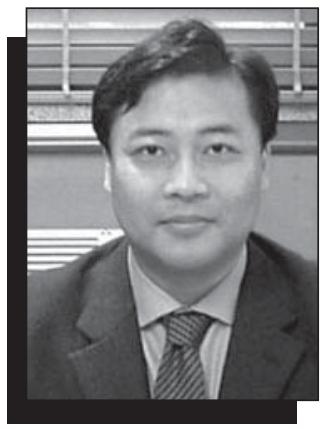

Seung-Yeop Kwak

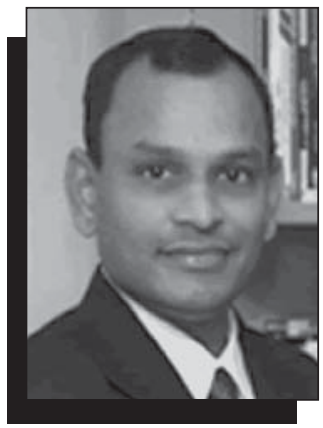

Seeram Ramakrishna

held at the Eighth

Annual Meeting of the

North American

Membrane Society to

honor Matsuura,

together with S.

Sourirajan, for their lifelong contributions to membrane research.

Matsuura can be

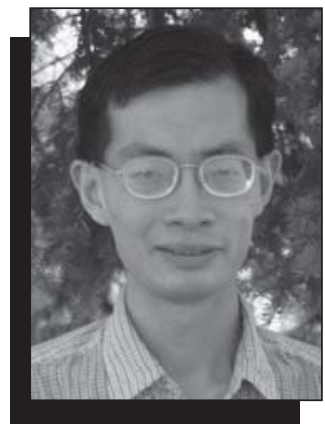

Kevin Leung

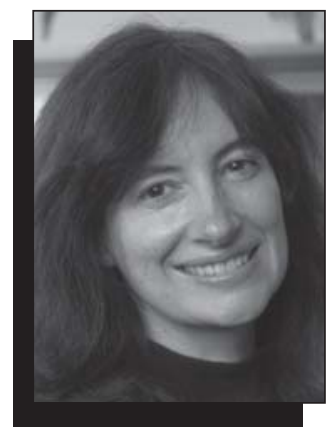

Susan B. Rempe

Environment and Water Research Institute (NEWRI).

$\mathrm{Ng}$ graduated from Queen Mary College, University of London, in 1977 with a BSc degree in civil engineering. $\mathrm{Ng}$ received his MSc degree in water resources engineering in 1978 from Birmingham University, and completed his $\mathrm{PhD}$ degree dissertation on chemical regeneration of activated carbon in 1980. He subsequently conducted postdoctoral research on biological treatment systems at Kyoto University, Japan.

His research interests are largely in the area of water purification and wastewater management. The focus of his efforts has been on investigations of water quality, treatment science, and the development of treatment technologies. 


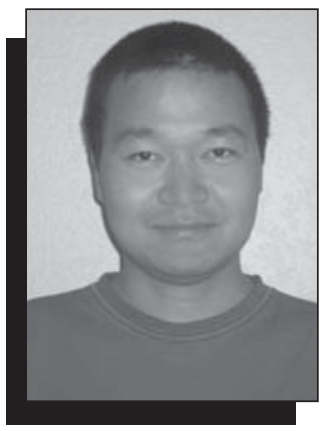

Juewen Liu

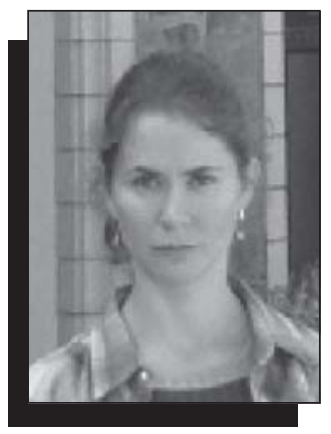

Nataly Vainrot

$\mathrm{Ng}$ can be reached at Nanyang Technological University, School of Civil and Environmental Engineering, Division of Environmental and Water Resources Engineering, 50 Nanyang Ave., Blk N1-01a-13, Singapore 639798; tel. +65-6790-6813 and e-mail wjng@ntu.edu.sg.

May D. Nyman is a Principal Member of the Technical Staff at Sandia National Laboratories. She holds a BS degree in geology, an MS degree in materials science, and $\mathrm{a} \mathrm{PhD}$ degree in chemistry.

At Sandia, Nyman has worked on the develop-

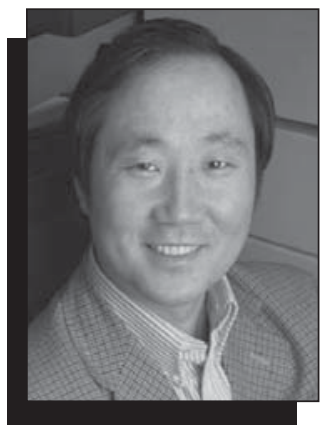

Yi Lu

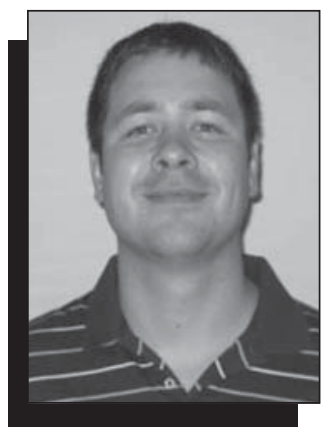

Daryl P. Wernette

ment of ion-exchange materials for radioactive waste treatment, luminescent materials, and coagulant materials for water treatment applications. Much of her work involves the discovery and exploitation of novel inorganic water-soluble clusters. Nyman's research interests are mainly focused on the synthesis of inorganic materials and understanding materials functionality at an atomic level.

Nyman can be reached at the Geochemistry Department, Sandia National Laboratories, Albuquerque, NM 871850754, USA; tel. 505-284-

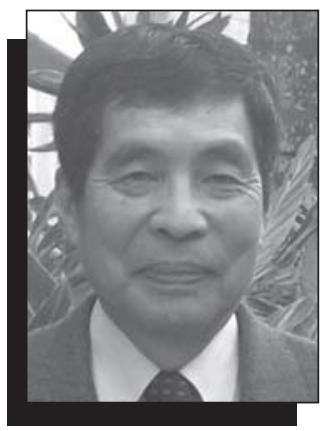

Takeshi Matsuura

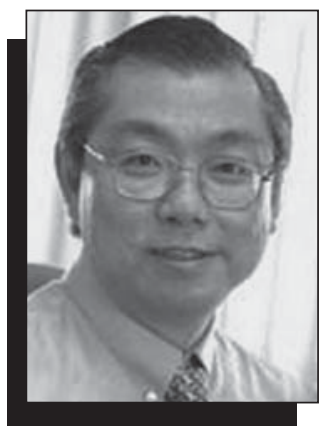

Wun Jern Ng

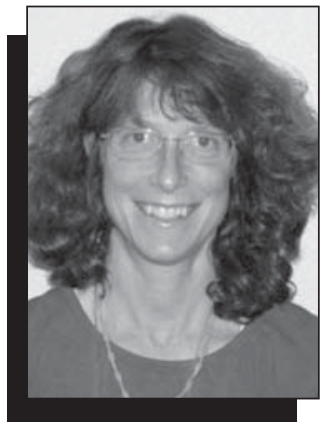

May D. Nyman
4484 and e-mail mdnyman@sandia.gov.

Seeram Ramakrishna has been dean of the Department of Mechanical Engineering at the National University of Singapore since 2003. He earned his $\mathrm{PhD}$ degree in materials science and engineering at the University of Cambridge in 1992.

Ramakrishna is an advisor to innovationdriven companies such as StemLife and NanoComposite Inc. He is a fellow of the Institution of Mechanical Engineers, U.K.; the Institution of Engineers, Singapore; the Institute of Materials, Minerals, and Mining, U.K.; and the American Institute for Medical and Biological Engineering.

He authored the first book on electrospinning, An Introduction to

Electrospinning and Nanofibers, and he serves on the editorial boards of 12 international journals.

Ramakrishna can be reached at the National University of Singapore,
Engineering Dean's Office, 10 Kent Ridge Crescent, Singapore 119260; tel. +65-6516-2142 and e-mail seeram@ nus.edu.sg.

Susan B. Rempe is a Principal Member of the Technical Staff in the Computational Systems Biology Group at Sandia National

Laboratories.

Rempe earned BA degrees from Columbia University and the University of Montana, and MS and PhD degrees in physical chemistry from the University of Washington. After holding a postdoctoral position at Los Alamos National Laboratory, Rempe joined Sandia in 2001.

Her research focuses on structure-function problems in molecular biophysics.

Rempe can be reached at the Computational Systems Biology Department, Sandia National Laboratories, Albuquerque, NM 871850895, USA; tel. 505-8450253 and e-mail slrempe@sandia.gov.
Nataly Vainrot is a $\mathrm{PhD}$ degree student under the supervision of I. Schechter at the Technion-Israel Institute of Technology in Haifa, Israel. She received her BA degree in chemistry from the Technion in 2000, and her MA degree in chemistry from the Technion in 2007, under the supervision of M.S. Eisen and R. Semiat.

Vainrot can be reached by e-mail at svnataly@ tx.technion.ac.il.

Daryl P. Wernette is an advanced scientist at the Science and Technology Center for Owens Corning in Granville, Ohio. He received his BS degree in chemistry from Michigan State University in 2002 and his $\mathrm{PhD}$ degree from the Department of Chemistry at the University of Illinois at Urbana-Champaign in 2007.

Wernette can be reached by e-mail at daryl.wernette@ owenscorning.com.

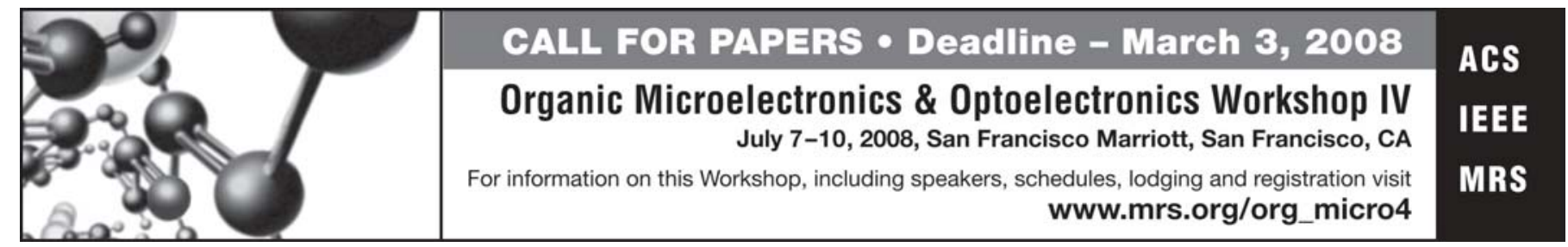

